\title{
Axial back pain in the athlete: pathophysiology and approach to rehabilitation
}

\author{
Chad Carlson
}

Published online: 7 May 2009

(c) The Author(s) 2009. This article is published with open access at Springerlink.com

\begin{abstract}
Back pain in athletes is common. Proper management of an athlete with back pain who is trying to return to competition must take into account the probable biomechanical contributors and incorporate these into a comprehensive rehabilitation program that moves steadily forward towards defined goals. This study will attempt to discuss pathological commonalities of low-back pain in athletes and how these can be applied to an evidence-based rehabilitation approach.
\end{abstract}

Keywords Back pain - Athlete - Spondylolysis ·

Disc herniation - Rehabilitation - Core - Core stability ·

Core strengthening

\section{Introduction}

Back pain is a common malady in sport, afflicting athletes across a wide range of pursuits with a reported incidence as high as 50\% [1] and an incidence of radiographic abnormalities that can range even higher [2]. The average incidence of degenerative low-back pain among all athletes is about 10-15\% [3], with gymnasts and football players most often affected [4]. Once begun, back problems have a tendency to become recurrent [5]. The root causes of back pain in athletes are varied and proper treatment and wellgrounded return-to-play decisions are dependent on proper diagnosis. With respect to methodology, however, there is a dearth of randomized trials assessing the effectiveness of specific rehabilitation protocols toward safe return-to-play

C. Carlson $(\bowtie)$

Stadia Sports Medicine, 6000 University Ave, Suite 250,

West Des Moines, IA 50266, USA

e-mail: ccarlson@stadiasportsmedicine.com for athletes with low-back pain. With these limitations in mind, this study will briefly review rehabilitation and return-to-play issues in athletes with back pain.

\section{Spectrum of disease}

The root causes of back pain in patients presenting to the physician's office vary according to the age of the patient [6], type of sport, or intrinsic issues such as body morphology. Children just entering puberty are felt to be at higher risk for the development of back problems due to a more vulnerable skeletal structure. Epidemiological studies of pre-adolescent athletes have shown an increased incidence of low-back pain over an inactive control population, as well as a direct association of development of low-back pain with a higher weekly training volume [7, 8]. When accompanied by more rigorous levels of activity, there is a high incidence of injury to the vertebral ring apophyses that is not seen in inactive age-matched controls [7]. Pre-adolescents have a $4 \%$ prevalence of pars stress fractures [9]. Adolescents have a higher incidence of posterior column injury in general, such as pars stress fractures or frank spondylolysis or spondylolisthesis. In one study of athletes presenting to a pediatric subspecialty spine clinic, $47 \%$ had a symptomatic spondylolysis, $26 \%$ had "hyperlordotic mechanical low-back pain" (posterior column pain from motion restriction patterns that stem from rapid growth), $11 \%$ had discogenic problems, $8 \%$ had symptomatic scoliosis and $6 \%$ had muscle strain. This contrasts with postteen adults, who by-far present more commonly with softtissue injury or acute disc-related problems [6].

Athletes in this age group often begin to exhibit a higher rate of symptomatic degenerative change in the spine [7]. It should also be emphasized that in the primary care setting, 
soft tissue-related etiologies are probably still the most common causes of low-back pain across all age groups.

Different sports convey different risks upon the back. Posterior column injuries such as spondylolysis occur at a higher rate in athletes who repetitively extend the spine, such as divers, gymnasts, interior football linemen, power lifters, cricket bowlers, and wrestlers. One study reported a spondylitic defect in one-third of collegiate football linemen [10]. Anterior column injuries such as disc degeneration or herniations occur more frequently in gymnasts, football players and power lifters [10-12]. Elite athletes are affected more frequently than non-elite athletes $[11,13]$.

\section{Risk factors for low-back pain}

The lumbar spine assists body movement through force production, force transmission, and shock absorption. Athletes consistently recruit or transfer high levels of repetitive force through the spine, and MRI has documented a higher rate of disc degeneration in athletes versus controls, $[13,14]$ though it is not clear that this translates to an increased incidence of pain.

In a weight bearing athlete, proper force transmission from the legs to, and through the spine is vital. Motion restriction at the hips or pelvis can lead to an overrecruitment of the lumbar spine, and has been associated with back pain in a non-athletic population. This relationship has not been firmly established in athletes [15-19]. Lack of extension at the back and an anterior pelvic tilt can be seen in patients with overly tight hip flexors, and has also been associated with a higher incidence of low-back pain [20-22]. Strong abdominal muscles typically would counteract this pelvic tilt, but when weak are unable to do so. The psoas muscle, which originates from the transverse processes of T12 to L5, also has fibers which originate from the intervertebral discs and the vertebral bodies themselves. Therefore, when the psoas is overly tight, the compressive load to the lumbar spine is increased [23]. Hamstring tightness has been consistently associated with the development of low-back pain, though a causal link has not been proven [24]. Shoulder capsule tightness in an overhead athlete can similarly prompt over-recruitment of the back. Recognition of these restrictions when present can be an important aspect of functional restoration.

Weak hip extensors have been associated with the presence of low-back pain, and in female athletes, the presence of hip weakness identified at the time of the preparticipation physical has even been shown to be predictive of the subsequent development of low-back pain [25-28]. There is also an established association between impairment of hip muscle function and post-traumatic ankle laxity $[29,30]$. Post-traumatic ankle laxity and lower extremity joint injury have been shown to correlate with a tendency to develop non-traumatic low-back pain among collegiate athletes, reinforcing the importance of evaluating the entire kinetic chain [19].

Sacral inclination (the anterior saggital tilt of the sacrum) is also thought to impact the tendency to develop low-back pain, with a smaller inclination angle being associated with a higher tendency for low-back pain (larger inclination angles bring the spine into greater lordosis, while smaller ones increase flexion moment at the spine) [18]. Although hamstring inflexibility is often cited in the literature as a cause of exaggerated lumbar lordosis, the posterior pelvic tilt that it would tend to induce would be anti-lordotic. In reality, tight hamstrings have not been shown to exert a significant effect on lumbar or pelvic mechanics $[31,32]$. Leg length inequality has also been suggested as an intrinsic risk factor in the development of low-back pain [33]. Finally, female athletes report a higher incidence of back problems than their male counterparts [27].

The normal extensor to flexor strength ratio is about 1.3 to 1 [34]. There are two types of lumbar extensors. The erector spinae are long muscles of thoracic origin which attach to the pelvis, creating a long moment arm for lumbar extension. The multifidus, which span individual segments, do not have these long moment arms, but the responsibility for segmental spinal stabilization rests largely on them [35]. The spine can be maintained in a "safe" neutral position with relatively low-grade contractions of these muscles, leading to the hypothesis that in many cases, the development of back problems arises not from lack of strength, but from a lack of endurance [36, 37]. In fact, the presence of increased axial strength, or increased lumbar extensor to flexor ratio, has been associated with higher levels of low-back pain in collegiate wrestlers, perhaps related to the fact that a greater vertical load is carried through the zygapophyseal joints in a relatively extended position [35, 38]. Fatigue has also been shown to negatively impair position sense of the spine [39]. Fatiguing flexion and extension back exercises induce angular changes in lateral bending and rotation [40-42]. There are documented cases of segmental buckling of the loaded spine into flexion with subsequent anterior column injury, thought to occur from localized motor control errors. This reinforces the importance of establishing proper neuromuscular control of the low-grade axial muscle contractions that maintain the spine in neutral [37]. Analysis of fatiguing exercise in the transverse plane confirms uniform contraction of the multifidus and rectus abdominus with motion to either side [42]. Transversus abdominus is consistently activated just prior to active use of the upper extremities, and during lumbar flexion and extension. It is felt that contraction of transversus abdominus provides a 
rigid "hoop" around the spine that imparts stability to it. Moreover, it's firing has been shown to be delayed among patients with low-back pain [43, 44]. The contraction of the diaphragm and pelvic floor similarly help provide rigidity to the spine through modulation of intra-abdominal pressure.

\section{Application of anatomical risks to a rehabilitation setting}

Attempts to prove the benefit of exercise as a therapy tool for low-back pain have been mixed, with some studies suggesting a benefit from rehab programs designed around intensive strengthening and others finding no benefit at all $[45,46]$. The results of core stability programs that attempt to influence the occurrence of low-back pain are also mixed $[25,47]$. In part, this may be due to the fact that specific interventions vary, and also that there is no uniformly accepted method to identify patients who have clinicallyrelevant core weakness. In patients with pre-existing back pain, however, a certain degree of core instability can be assumed. Thus, in most cases, the goal of early rehabilitation should be segmental stability, followed by optimization of intersegmental control [48]. This often must be accomplished in the face of superficial muscle groups that over-fire through maladaptation patterns that ultimately increase spinal compression load. Ebenbichler [49] divided the muscular targets of back rehabilitation into the following helpful conceptual framework: (1) local paravertebral muscles that provide intersegmental stabilization. (2) Polysegmental paravertebral muscles that protect the spine in neutral and balance external loads during weight transfer. (3) Muscles that contribute to facilitation of intraabdominal pressure, providing global spinal stability. (4) Muscles that act on the fascia supports of the back to influence spinal stiffness.

The lumbar multifidus have superficial fibers which span up to five segments to provide a small extension lever arm. The deeper fibers of multifidus span fewer segments and attach to the facets and mammillary process of the superior articular facet. Multifidus is able to exert spinal control through spinal compression with minimal extension, due to their proximity to the center of rotation [48]. The multifidus quickly atrophy once back pain occurs, with an accompanying reduction of intersegmental control [50, 51]. In biomechanical research models, loss of even one segment of muscular control has been shown to significantly reduce the overall stability of the spine [52]. In patients who do not incorporate directed exercise into a rehabilitation program, this atrophy has been shown to persist even after the back pain has cleared [53, 54]. Multifidus can be targeted with exercises such as unilateral hip extension while prone with knees bent, or by alternating shoulder flexion with hand weights while standing on a balance board and consciously bracing the abdomen. Both of these exercises carry relatively lower levels of force transmission through the spine. The former exercise also targets gluteus maximus well, which is known to fatigue in patients with low-back pain [55]. The transversus abdominus has attachments to the pelvis, ribs and thoracolumbar fascia, and contracts symmetrically in patients without low-back pain prior to conscious initiated movement of the extremities, imparting stiffness to the spine in anticipation of motor activity. This contraction is significantly delayed in patients with back pain $[43,56,57]$. Transversus abdominus can be targeted without much cost to the spine by having the patient "hollow in" their abdominal wall [37]. Directed rehabilitation efforts focused on restoration of multifidus and transversus abdominus function have been shown to reduce recurrence of low back pain episodes with benefits over the control group persisting through a 3 year monitoring period [58]. Quadratus lumborum has also been shown to impart significant stability to the lumbar spine [59]. These muscle groups can be targeted with the use of therapeutic exercise that maintains the spine in a relative neutral position. The side bridge exercise has been identified as one that preferentially contracts quadratus lumborum while minimizing spinal load [37]. McGill has published sex-specific estimated normative values for endurance of the quadratus lumborum, flexors, and extensors, involving time that the tested individual can hold position without breaking form. These may be helpful in identifying patients whose current functional status fall far short of estimated norms. Normative ratios for the side bridge and flexors are expressed in terms of percentage of time that position can be held relative to the extensors, which consistently have the highest endurance of all tested muscle groups. Typically, men can hold the side bridge position for $65 \%$ of total extensor hold time, while women average $39 \%$ of their extensor time [59].

As endurance within the inner core starts to improve, the focus of rehabilitation can expand outward to include muscle groups which both control directional movement and assist in spinal stabilization, such as the abdominal obliques, rectus abdominus, or erector spinae. Studies assessing the efficacy of core stability training in low-back pain patients are encouraging. Directed core training in patients with spondylolisthesis has been shown to reduce the likelihood of recurrence at 3 years over controls by over $1,200 \%$ [47, 58].

In controlling movement at the spine, the nervous system prefers controlled motion over spinal compression to maintain stability [48]. Recent research that has looked at the compressive load imparted to the spine with traditional abdominal exercise has shown that in many cases, these 
activities impart an unacceptably high risk to the injured athlete. Traditional sit-ups, leg lifts, or pelvic tilts (which are non-functional exercises anyway) have been specifically identified as such [35]. In contrast, exercises such as curl-ups or horizontal side bridges have a high abdominal challenge to lumbar compression ratio [60].

Once abdominal control has improved, rehabilitation should begin to move toward sport-specificity, with reproduction of movements that were formally painful as patient tolerance improves. Sport-specific movement patterns can initially be broken down into shorter skill segments, with integration occurring later as the athlete's capabilities increase [48]. Hodges describes a five-phase progression of motor learning that is a good philosophical groundwork for efforts at rehabilitation in this arena. This sequence includes (1) skill learning, (2) precision training, (3) controlled activation in a variety of postures and positions, (4) integration of segmental stability exercise with tasks that activate the superficial trunk stabilizers, and (5) specific functional retraining in a sport-specific context [48]. Isolation of the long extensors is best done by keeping the patient in a neutral pelvic position, which in-turn requires a stable pelvic platform [61]. Although rehabilitation should be initiated on a stable surface, the goal should be to move toward more challenging activities, using both unstable platforms and sudden perturbations that the athlete must counter, and demanding maintenance of stability in both spine neutral and non-neutral positions [35, 58]. One study that looked at intensive back extensor strength training (presumably over-emphasizing the superficial extensors) showed a corresponding loss of postural control that could be avoided through concomitant balance training [62].

As proprioceptive capabilities improve, progressive sport-specific plyometric activities can be incorporated into the athlete's rehabilitation program. Knowledge of specific patterns that relate to participation in any given sport is helpful when attempting to devise a rehabilitation program for athletes. For example, tennis players commonly exhibit an extensor-to-flexor ratio that favors the flexors-a possible target for attempts at restoration of balance [63]. Rehab programs at this point should also begin to replicate the chaos that sports participation often reflects. Standaert and Herring suggest that the program at this stage be so biomechanically chaotic that the athlete's sport-related demands are relatively simple by comparison. This would include multiplanar demands on motion with sudden accelerations and decelerations, asymmetric loads and loads imposed during motion $[64,65]$.

While endurance, proprioception, and strengthening exercises are progressing, attention should be given to biomechanical contributors that can be corrected, such as significant muscle inflexibility patterns around the hips.
Aerobic exercise should also be incorporated into the athlete's program, since this has been shown to improve mood during rehab, and since maintenance of aerobic fitness is a prerequisite for effective return-to-play [66]. Mention should also be made of the fact that psychological factors are stronger predictors of chronic back pain than biomechanical or medical factors. Gain issues associated with injury and recovery should be identified early and addressed [67].

One prospective study of athletes with spondylolysis or spondylolisthesis who underwent rehabilitation through a program designed along the principles outlined above showed that it took, on average, 4-5 weeks of specific core training before accurate coordinated motor patterns could be established [47]. This is the baseline requirement for the athlete's rehabilitation to then progress towards more dynamic sport-specificity. In all, return-to-play decisions need to be individualized according to the pathology involved, the demands of the sport and the personality of the injured athlete, but some constants exist. Athletes should have full motion without pain, grossly normal strength, and demonstrate ability to perform both core stability exercises and sport-specific skill sets on cue and without pain. Aerobic conditioning should be appropriate for return. Once these conditions have been met, it can be reasonably assumed that the risks of sports participation are acceptable, and the athlete can be transitioned with confidence.

\section{Conclusion}

Back pain in sport is common. Although the causes are varied, it can be assumed that core instability occurs nearly universally in symptomatic athletes. A rehabilitation program which targets this unstable base first, and then progresses out toward control of movement in a sport-specific fashion, is a reasonable approach that should result in pain reduction, skill enhancement and a safe return-to-play.

Open Access This article is distributed under the terms of the Creative Commons Attribution Noncommercial License which permits any noncommercial use, distribution, and reproduction in any medium, provided the original author(s) and source are credited.

\section{References}

1. d'Hemecourt PA, Gerbino PG 2nd, Micheli LJ. Back injuries in the young athlete. Clin Sports Med. 2000;19(4):663-79.

2. Sward L, et al. Back pain and radiologic changes in the thoracolumbar spine of athletes. Spine. 1990;15(2):124-9.

3. Gerbino PG, d'Hemecourt PA. Does football cause an increase in degenerative disease of the lumbar spine? Curr Sports Med Rep. 2002;1(1):47-51. 
4. Keene JS, et al. Back injuries in college athletes. J Spinal Disord. 1989;2(3):190-5.

5. Taimela S, et al. The prevalence of low back pain among children and adolescents. A nationwide, cohort-based questionnaire survey in Finland. Spine. 1997;22(10):1132-6.

6. Micheli LJ, Wood R. Back pain in young athletes. Significant differences from adults in causes and patterns. Arch Pediatr Adolesc Med. 1995;149(1):15-8.

7. Kujala UM, et al. Low-back pain in adolescent athletes. Med Sci Sports Exerc. 1996;28(2):165-70.

8. Kujala UM, et al. Subject characteristics and low back pain in young athletes and nonathletes. Med Sci Sports Exerc. 1992;24(6):627-32.

9. Kraft DE. Low back pain in the adolescent athlete. Pediatr Clin North Am. 2002;49(3):643-53.

10. Tall RL, DeVault W. Spinal injury in sport: epidemiologic considerations. Clin Sports Med. 1993;12(3):441-8.

11. Sward L, et al. Disc degeneration and associated abnormalities of the spine in elite gymnasts. A magnetic resonance imaging study. Spine. 1991;16(4):437-43.

12. Videman $\mathrm{T}$, et al. Lifetime exercise and disk degeneration: an MRI study of monozygotic twins. Med Sci Sports Exerc. 1997;29(10):1350-6.

13. Ong A, Anderson J, Roche J. A pilot study of the prevalence of lumbar disc degeneration in elite athletes with lower back pain at the Sydney 2000 Olympic Games. Br J Sports Med. 2003;37(3): 263-6.

14. Lundin $\mathrm{O}$, et al. Back pain and radiological changes in the thoraco-lumbar spine of athletes. A long-term follow-up. Scand J Med Sci Sports. 2001;11(2):103-9.

15. Fairbank JC, et al. Influence of anthropometric factors and joint laxity in the incidence of adolescent back pain. Spine. 1984;9(5): 461-4.

16. Mellin G. Correlations of hip mobility with degree of back pain and lumbar spinal mobility in chronic low-back pain patients. Spine. 1988;13(6):668-70.

17. Mellin G. Decreased joint and spinal mobility associated with low back pain in young adults. J Spinal Disord. 1990;3(3):238-43.

18. Sward L, Eriksson B, Peterson L. Anthropometric characteristics, passive hip flexion, and spinal mobility in relation to back pain in athletes. Spine. 1990;15(5):376-82.

19. Nadler SF, et al. Low back pain in college athletes. A prospective study correlating lower extremity overuse or acquired ligamentous laxity with low back pain. Spine. 1998;23(7):828-33.

20. Triano JJ, Schultz AB. Correlation of objective measure of trunk motion and muscle function with low-back disability ratings. Spine. 1987;12(6):561-5.

21. Kujala UM, et al. Lumbar mobility and low back pain during adolescence. A longitudinal three-year follow-up study in athletes and controls. Am J Sports Med. 1997;25(3):363-8.

22. Pope $\mathrm{MH}$, et al. The relationship between anthropometric, postural, muscular, and mobility characteristics of males ages 18-55. Spine. 1985;10(7):644-8.

23. N B. Clinical anatomy of the lumbar spine and sacrum. 3rd ed. New York: Churchill-Livingstone; 1997.

24. Plowman SA. Physical activity, physical fitness, and low back pain. Exerc Sport Sci Rev. 1992;20:221-42.

25. Nadler SF, et al. Hip muscle imbalance and low back pain in athletes: influence of core strengthening. Med Sci Sports Exerc. 2002;34(1):9-16.

26. Kankaanpaa M, et al. Back and hip extensor fatigability in chronic low back pain patients and controls. Arch Phys Med Rehabil. 1998;79(4):412-7.

27. Nadler SF, et al. Relationship between hip muscle imbalance and occurrence of low back pain in collegiate athletes: a prospective study. Am J Phys Med Rehabil. 2001;80(8):572-7.
28. Leinonen V, et al. Back and hip extensor activities during trunk flexion/extension: effects of low back pain and rehabilitation. Arch Phys Med Rehabil. 2000;81(1):32-7.

29. Beckman SM, Buchanan TS. Ankle inversion injury and hypermobility: effect on hip and ankle muscle electromyography onset latency. Arch Phys Med Rehabil. 1995;76(12):1138-43.

30. Bullock-Saxton JE, Janda V, Bullock MI. The influence of ankle sprain injury on muscle activation during hip extension. Int $\mathrm{J}$ Sports Med. 1994;15(6):330-4.

31. Gajdosik RL. Hamstring stretching and posture. Phys Ther. 1997;77(4):438-9.

32. Li Y, McClure PW, Pratt N. The effect of hamstring muscle stretching on standing posture and on lumbar and hip motions during forward bending. Phys Ther. 1996;76(8):836-45. discussion 845-9.

33. Giles LG, Taylor JR. Low-back pain associated with leg length inequality. Spine. 1981;6(5):510-21.

34. Trainor TJ, Wiesel SW. Epidemiology of back pain in the athlete. Clin Sports Med. 2002;21(1):93-103.

35. Akuthota V, Nadler SF. Core strengthening. Arch Phys Med Rehabil. 2004;85(3 Suppl 1):S86-92.

36. Cholewicki J, McGill SM. Mechanical stability of the in vivo lumbar spine: implications for injury and chronic low back pain. Clin Biomech (Bristol, Avon). 1996;11(1):1-15.

37. McGill SM. Low back stability: from formal description to issues for performance and rehabilitation. Exerc Sport Sci Rev. 2001;29(1):26-31.

38. Iwai $\mathrm{K}$, et al. Trunk muscle strength and disability level of low back pain in collegiate wrestlers. Med Sci Sports Exerc. 2004;36(8):1296-300.

39. Taimela S, Kankaanpaa M, Luoto S. The effect of lumbar fatigue on the ability to sense a change in lumbar position. A controlled study. Spine. 1999;24(13):1322-7.

40. Parnianpour M, et al. 1988 Volvo award in biomechanics. The triaxial coupling of torque generation of trunk muscles during isometric exertions and the effect of fatiguing isoinertial movements on the motor output and movement patterns. Spine. 1988;13(9):982-92.

41. Marras WS, Granata KP. Changes in trunk dynamics and spine loading during repeated trunk exertions. Spine. 1997;22(21): 2564-70.

42. $\mathrm{Ng} \mathrm{JK}$, et al. Effect of fatigue on torque output and electromyographic measures of trunk muscles during isometric axial rotation. Arch Phys Med Rehabil. 2003;84(3):374-81.

43. Hodges PW, Richardson CA. Inefficient muscular stabilization of the lumbar spine associated with low back pain. A motor control evaluation of transversus abdominis. Spine. 1996;21(22):2640-50.

44. Cresswell AG, Grundstrom H, Thorstensson A. Observations on intra-abdominal pressure and patterns of abdominal intra-muscular activity in man. Acta Physiol Scand. 1992;144(4):409-18.

45. Koes BW, et al. Physiotherapy exercises and back pain: a blinded review. BMJ. 1991;302(6792):1572-6.

46. Carpenter DM, Nelson BW. Low back strengthening for the prevention and treatment of low back pain. Med Sci Sports Exerc. 1999;31(1):18-24.

47. O'Sullivan PB, et al. Evaluation of specific stabilizing exercise in the treatment of chronic low back pain with radiologic diagnosis of spondylolysis or spondylolisthesis. Spine. 1997;22(24):2959-67.

48. Hodges PW. Core stability exercise in chronic low back pain. Orthop Clin North Am. 2003;34(2):245-54.

49. Ebenbichler GR, et al. Sensory-motor control of the lower back: implications for rehabilitation. Med Sci Sports Exerc. 2001; 33(11):1889-98.

50. Moseley GL, Hodges PW, Gandevia SC. External perturbation of the trunk in standing humans differentially activates components of the medial back muscles. J Physiol. 2003;547(Pt 2):581-7. 
51. Leinonen V, et al. Disc herniation-related back pain impairs feedforward control of paraspinal muscles. Spine. 2001;26(16):E36772.

52. Crisco JJ, III, Panjabi MM. The intersegmental and multisegmental muscles of the lumbar spine. A biomechanical model comparing lateral stabilizing potential. Spine. 1991;16(7):793-9.

53. Hides JA, Richardson CA, Jull GA. Multifidus muscle recovery is not automatic after resolution of acute, first-episode low back pain. Spine. 1996;21(23):2763-9.

54. Hides JA, et al. Evidence of lumbar multifidus muscle wasting ipsilateral to symptoms in patients with acute/subacute low back pain. Spine. 1994;19(2):165-72.

55. Arokoski JP, et al. Back and hip extensor muscle function during therapeutic exercises. Arch Phys Med Rehabil. 1999;80(7):84250.

56. Hodges PW, Richardson CA. Contraction of the abdominal muscles associated with movement of the lower limb. Phys Ther. 1997;77(2):132-42. discussion 142-4.

57. Hodges PW, Richardson CA. Delayed postural contraction of transversus abdominis in low back pain associated with movement of the lower limb. J Spinal Disord. 1998;11(1):46-56.

58. Hides JA, Jull GA, Richardson CA. Long-term effects of specific stabilizing exercises for first-episode low back pain. Spine. 2001;26(11):E243-8.

59. McGill SM, Childs A, Liebenson C. Endurance times for low back stabilization exercises: clinical targets for testing and training from a normal database. Arch Phys Med Rehabil. 1999;80(8):941-4.

60. Axler CT, McGill SM. Low back loads over a variety of abdominal exercises: searching for the safest abdominal challenge. Med Sci Sports Exerc. 1997;29(6):804-11.

61. Graves JE, et al. Pelvic stabilization during resistance training: its effect on the development of lumbar extension strength. Arch Phys Med Rehabil. 1994;75(2):210-5.

62. Kollmitzer J, et al. Effects of back extensor strength training versus balance training on postural control. Med Sci Sports Exerc. 2000;32(10):1770-6.

63. Ellenbecker TS, Roetert EP. An isokinetic profile of trunk rotation strength in elite tennis players. Med Sci Sports Exerc. 2004;36(11):959-63.

64. Standaert CJ, Herring SA, Pratt TW. Rehabilitation of the athlete with low back pain. Curr Sports Med Rep. 2004;3(1):35-40.

65. Young JL, Press JM, Herring SA. The disc at risk in athletes: perspectives on operative and nonoperative care. Med Sci Sports Exerc. 1997;29(7 Suppl):S222-32.

66. Sculco AD, et al. Effects of aerobic exercise on low back pain patients in treatment. Spine J. 2001;1(2):95-101.

67. Linton SJ, Hallden K. Can we screen for problematic back pain? A screening questionnaire for predicting outcome in acute and subacute back pain. Clin J Pain. 1998;14(3):209-15. 